\title{
Clinical comparison of fournier's gangrene to other necrotizing soft tissue infections
}

\author{
Yana Puckett, Brian Fisher and Sharmila Dissanaike* \\ *Correspondence: sharmila.dissanaike@ttuhsc.edu

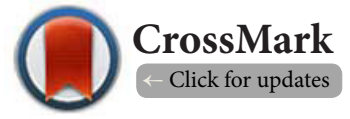

Department of General Surgery, Texas Tech University Health Sciences Center, Lubbock, Texas, USA.

\begin{abstract}
Background: The purpose of this study was to review key differences between necrotizing soft tissue infections (NSTI) and Fournier's Gangrene (FG) in demographics, comorbidities, laboratory findings, cost, and clinical course.

Methods: The burn registry of a Level 1 trauma and burn center in Lubbock, Texas was used to identify and retrospectively review medical records of patients with NSTIs and FG from 2003 to 2012. Bivariate analysis on the FG subgroup was performed and compared to all other NSTI using Fisher's exact test for proportions and Student's t-test to compare continuous variables with equal variance assumed. A $p<0.05$ was considered to be significant.

$\underline{\text { Results: }}$ We found that 133 patients met inclusion criteria. Analysis of data revealed that FG had longer length of hospital stay $(p=0.02)$ and an increased number of operations performed $(p=0.01)$ than other NSTIs. There was also a higher association with diabetes in $\mathrm{FG}(\mathrm{p}=0.03)$ and polymicrobial infections $(\mathrm{p}=0.01)$. Intravenous drug abuse was found to be more associated with NSTIs compared to FG ( $\mathrm{p}=0.03)$. Conclusion: Our study showed that FG patients have longer length of hospital stay, lower hemoglobin levels, and increased number of operations. NSTIs were more likely to be associated with intravenous drug abuse. There is no difference in rates of mortality between the two groups.
\end{abstract}

Keywords: NSTI, Necrotizing fasciitis, fasciitis, fournier's gangrene, clinical comparison, soft tissue infections, cost, treatment differences, polymicrobial, intravenous drug use, diabetes, obesity, surgical excision, debridement, length of stay

\section{Introduction}

Necrotizing soft tissue infections (NSTIs) were first described by Hippocrates in 500 BC. These infections are characterized by soft tissue necrosis that occurs very quickly and becomes lethal if not treated early. In severe disease, there is rapid spread that often leads to systemic shock, sepsis, and ultimately death [1-8]. Some of the risk factors associated with NSTIs include Type 2 Diabetes Mellitus (DM2), obesity, smoking, immobility, alcohol abuse, cirrhosis of the liver, HIV, intravenous drug abuse (IVDA), and malnutrition $[9,10]$. Treatment typically includes early broad-spectrum intravenous (IV) antibiotics, fluid resuscitation, vasopressor support, and extensive debridement [1,11-17].

Fournier's Gangrene (FG) is a subset of NSTIs. It was initially described by the French dermatologist and venerologist JeanAlfred Fournier (1832-1914) in 1883. FG separates itself from other NSTIs in that it involves the perineum [18-20]. Historically,
FG was a diagnosis limited to males only [21,22], however, it is now also a diagnosis in women as we now realize that the pathophysiology of the disease is the same [23-25]. DM2 is a risk factor that is known to be more strongly linked to FG compared to other NSTIs [26-28]. The treatment of FG is similar to other NSTIs and includes IV antibiotics, supportive treatment, and early debridement [29-32].

This study compared clinical differences between FG and other NSTIs. We elected to compare the differences in diagnosis, surgical and medical treatment, microbiota, laboratory results, treatment, and length of stay in the hospital. Clinical outcomes, cost differences, demographics, and co-morbid illnesses were also compared.

\section{Methods}

This retrospective review was approved by the Texas Tech 
University Health Sciences Center Institutional Review Board. Subjects were identified using the discharge database at University Medical Center, a tertiary referral hospital which includes a regional burn center in Lubbock, TX. Patients who were admitted to the hospital between 2003 and 2012 were screened for ICD-9 codes of 728 and 785 as discharge diagnoses. The diagnoses were then confirmed to be necrotizing infections through manual review of medical records. Cases were subsequently sub-divided into FG and all other NSTIs. FG was defined as any necrotizing fulminant soft tissue infection with local tissue destruction in the perineal region in both men and women. "Other NSTI" was defined as any necrotizing fulminant soft tissue infection with local tissue destruction in any other area of the body, without perineal involvement. For this study, subjects were categorized into one of these groups based on the clinical description obtained by chart review matching the above definition, or explicit documentation of the diagnosis in the chart by the treating physicians.

Differences in diagnosis, laboratory results, treatment, length of stay in the hospital, outcomes, cost differences, demographics, and co-morbid illnesses were assessed between the two groups. While a significant portion of our patient population are transferred from smaller regional hospitals, these subjects were excluded from the study, as initial presenting laboratory data, length of stay, or number of operations could not accurately be accounted for. Patients who were identified by discharge diagnosis codes, but whose primary diagnosis and reason for admission was a different medical or surgical condition were also excluded from analysis.

\section{Treatment of NSTI and FG at Our Institution}

The burn and wound care service at Texas Tech University Health Sciences Center in Lubbock, a well-established service staffed by general surgeons with specialty expertise in this field, are routinely consulted for all patients admitted to the hospital with known or suspected NSTI. Based on the location of infection and status of the patient, medical, orthopedic, urologic, and gynecological services may also be consulted. All patients requiring intensive care unit (ICU) level care are admitted and managed primarily by the burn and wound service. This includes nurses with extensive training and experience in management of these often large and difficult wounds.

Routine initial care includes urgent operative debridement after initial rapid resuscitation. Patients admitted to the ICU usually have their wounds left completely open for 24-48 hours. Lubricant gel is applied over muscle. Bedside spritzing of open areas with antibiotic solution every few hours to prevent desiccation is performed. These patients are monitored continuously for signs of recurrence and/or disease progression. In anatomic locations where this is not feasible, such as in obese FG patients where skin folds prevent airing of the wound, the wound is packed loosely with wetto dry dressings instead. Wounds are routinely evaluated at bedside by the operating team at least every 12 hours. Plans for repeat debridement based on this evaluation rather than a scheduled operative take-back is the usual practice.

Broad spectrum antibiotic coverage is used on all FG and NSTI patients. De-escalation of antibiotics after identification of responsible organisms is routinely applied. Other supportive care is based on standard protocols for sepsis. Enteral nutrition is started immediately on both NSTI and FG patients unless they have escalating vasopressor requirements. Continuous renal replacement is initiated in cases of renal failure. Low tidal volume ventilation modes are used in the rare event that adult respiratory distress syndrome develops secondary to these infections.

After the infection has been resected and further spread is not evident on clinical evaluation, a vacuum assisted dressing is applied to all wounds. If this is not feasible due to the anatomic location or body habitus, then antibiotic-ointment and non-stick dressing is used as a daily dressing. The patient is discharged home or to a nursing facility until a healthy granulation bed has been achieved. Skin grafting or flap coverage is performed by the same surgical service, which also follows the patients in the outpatient clinic.

Microbiologic Processing of Specimens at Our Institution All specimens were processed by the same laboratory using standard operating procedures derived from the Manual of Clinical Microbiology (currently $10^{\text {th }}$ ed., ASM Press, Washington D.C., 2011) and Clinical Microbiology Procedure Handbook (currently $3^{\text {rd }}$ ed., ASM Press, Washington D.C., 2011). Antibiotic sensitivities are reported according to CLSI (Clinical and Laboratory Standards Institute) M100 document. No significant changes in specimen processing or reporting occurred during this time period.

\section{Data collection}

Medical records were reviewed for the following: age; sex; body mass index (BMI); presenting vital signs; maximal or minimal laboratory values for indicated values over the course of their initial hospital admission; evidence of infection; co-morbid illnesses such as hyperlipidemia, heart disease, hypertension, peripheral vascular disease, DM2; substance abuse including tobacco, IV drugs, and alcohol; length of stay; time to diagnosis and surgery; number of surgeries; specific microbes isolated from areas of necrosis; anatomical location of the infection; number of microbes isolated; and mortality. Time to diagnosis was considered the time the patient arrived to the emergency room (ER) to the first chart documentation of NSTI or FG as a primary diagnosis.

\section{Statistical analysis}

A commercially available statistical software package (SPSS Inc. Chicago, III, USA, Version 22) was used for the statistical analysis. Bivariate analysis on the FG subgroup was performed and compared to all other NSTI using Fisher's exact test for 
proportions and Student's t-test to compare continuous variables with equal variance assumed. A $p<0.05$ was considered to be significant. Due to the FG group comprising only 33 individuals, multivariate analysis was not performed.

\section{Results}

One hundred and thirty-three patients with NSTI were admitted with a primary diagnosis of acute NSTI or FG between January 1, 2003 and April 30, 2012. Of these patients, 33 (25\%) were diagnosed with FG while $100(75 \%)$ had other NSTIs in an assortment of anatomic locations. Of the patients with $\mathrm{FG}$, $20(61 \%)$ were male, mean age was 53.0 , and BMI was 36.0 . In comparison, of patients diagnosed with NSTI $56(56 \%)$ were male, mean age was 49.6, and BMI was 32.1 (Table 1).

Table 1. Comparison of demographics in Fournier's gangrene to NSTI in other locations.

\begin{tabular}{llll}
\hline & NSTI & FG & P-value \\
\hline Age (years) & $49.6(10-85)$ & $53.0(26-92)$ & 0.24 \\
BMI & $32.1(16-61)$ & $36.0(19-67)$ & 0.13 \\
Male gender & $56.0 \%$ & $60.6 \%$ & 0.69 \\
Hyperlipidemia & $16 \%$ & $18 \%$ & 0.76 \\
Heart disease & $21 \%$ & $26 \%$ & 0.58 \\
Hypertension & $57 \%$ & $71 \%$ & 0.34 \\
PVD & $12 \%$ & $5 \%$ & 0.45 \\
Diabetes mellitus & $56 \%$ & $78 \%$ & 0.03 \\
IV drug abuse & $30 \%$ & $0 \%$ & 0.03 \\
Tobacco use & $27 \%$ & $33 \%$ & 0.34 \\
Alcohol use & $24 \%$ & $16 \%$ & 0.29 \\
\hline
\end{tabular}

FG: Fournier's gangrene; NSTI: Necrotizing soft tissue infection other than Fournier's; BMI: Body mass Index; PVD: Peripheral vascular disease; IV: Intravenous

In patients with NSTIs other than FG, the lower extremities were most frequently affected $(50 \%)$, followed by the upper extremity (23\%) and the abdomen (16\%). In the other 11 patients with NSTI, infection was found on the buttocks (3\%), chest (2\%), head (1\%), back (1\%), or in multiple locations (4\%). By definition, the perineum was infected in all patients with FG. It was the sole area affected in $15(45 \%)$ patients while in the remaining 18 (55\%) patients the infection spread to the surrounding tissues including the abdomen, buttocks, and lower extremity.

Patients with FG and NSTI presented similarly in their initial vital signs and laboratory values except for hemoglobin levels. The mean hemoglobin of patients with FG was 10.5 while those with NSTI was $11.6(p=0.03)$ (Table 2). They also tended to have similar rates of hyperlipidemia, heart disease, hypertension, and peripheral vascular disease. In addition, there were comparable rates of tobacco and alcohol use
Table 2. Comparison of clinical data in Fournier's gangrene to NSTI in other locations.

\begin{tabular}{llll}
\hline & NSTI & FG & P-value \\
\hline Prealbumin & $7.6(2-26)$ & $7.8(2-27)$ & 0.89 \\
Highest CRP & $27.6(1-334)$ & $18.4(6-42)$ & 0.40 \\
Lowest sodium & $131.2(106-145)$ & $132.6(123-143)$ & 0.18 \\
Highest creatinine & $1.9(0-11)$ & $1.93(1-6)$ & 0.65 \\
Highest glucose & $237.1(79-1400)$ & $238.6(93-484)$ & 0.96 \\
Sodium & $133.4(121-154)$ & $135.0(123-148)$ & 0.18 \\
Creatinine & $1.5(0.3-10.3)$ & $1.3(0.4-4.4)$ & 0.51 \\
BUN & $25.3(1-102)$ & $27.6(7-91)$ & 0.58 \\
Glucose & $179.4(29-745)$ & $188.9(63-449)$ & 0.71 \\
Calcium & $8.1(4-12)$ & $8.2(6-11)$ & 0.61 \\
Phosphate & $3.9(1-10)$ & $3.6(1-6)$ & 0.27 \\
WBC (in thousands) & $16.7(1-51)$ & $18.2(1-45)$ & 0.44 \\
Hemoglobin & $11.6(6-19)$ & $10.5(4-15)$ & 0.03 \\
Platelets (in thousands) & $260.6(13-804)$ & $321.0(25-1029)$ & 0.08 \\
Temperature & $98.8(92-105)$ & $98.9(96-102)$ & 0.83 \\
DBP & $70.2(40-118)$ & $68.5(38-100)$ & 0.64 \\
Heart rate & $45.4(56-153)$ & $41.1(68-142)$ & 0.59 \\
Respiratory rate & $20.3(9-106)$ & $20.2(15-40)$ & 0.97 \\
Oxygen saturation & $96.1(73-100)$ & $97.2(90-100)$ & 0.21 \\
\hline
\end{tabular}

FG: Fournier's gangrene; NSTI: Necrotizing soft tissue infection other than Fournier's; CRP: C-reactive protein; WBC: White blood cell count; DBP: Diastolic blood pressure; BUN: Blood urea nitrogen ${ }^{*}$ Unless otherwise noted the value was obtained at admission

among both groups. However, $78 \%$ of patients with FG had been diagnosed with diabetes mellitus while $56 \%$ of NSTI patients had received a diagnosis $(p=0.03)$. IV drug abuse was reported in $30 \%$ of those in the NSTI group and $0 \%$ in FG group ( $p=0.03$ ) (Table 1).

There was a greater incidence of poly-microbial infections in the FG group (64\%) than those in the NSTI group (38\%) $(p=0.01)$ (Figure 1$)$. The results of the cultures were available for all patients except for 5 in the NSTI group. Of those patients with a poly-microbial infection, $66 \%$ of patients with in NSTI and $73 \%$ in FG had a component of Staph species, strep species, or both. There were two patients in the FG group that had four separate species isolated and one patient in the NSTI group which had six species isolated (Figure 1). Within the two groups, we also analyzed the data to see if there was an association between number of microbes and mortality rate. There was no difference in number of infectious organisms in survivors versus non-survivors in either group $(p=0.87)$. A variety of organisms were isolated within each group but the most common in NSTI group was a combination (32\%), Staphylococcus aureus (20\%), Streptococcus pyogenes $(17 \%)$, and gram negatives not otherwise specified (6\%). In $\mathrm{FG}$, a combination of organisms was most common (60\%) 
followed by staph aureus (15\%), other organisms (9\%), and candida (6\%) (Figure 2).

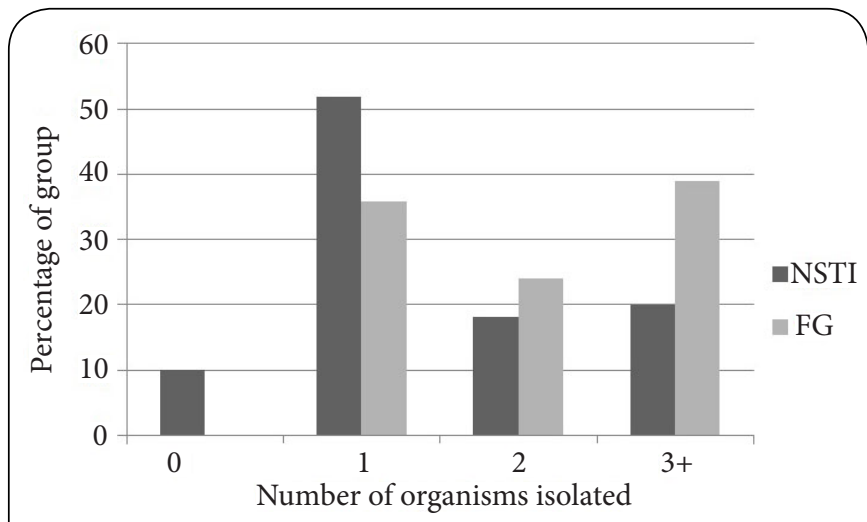

Figure 1. Comparison of number of organisms isolated from necrotic tissue.

FG: Fournier's gangrene; NSTI: Necrotizing soft tissue infection other than Fournier's.

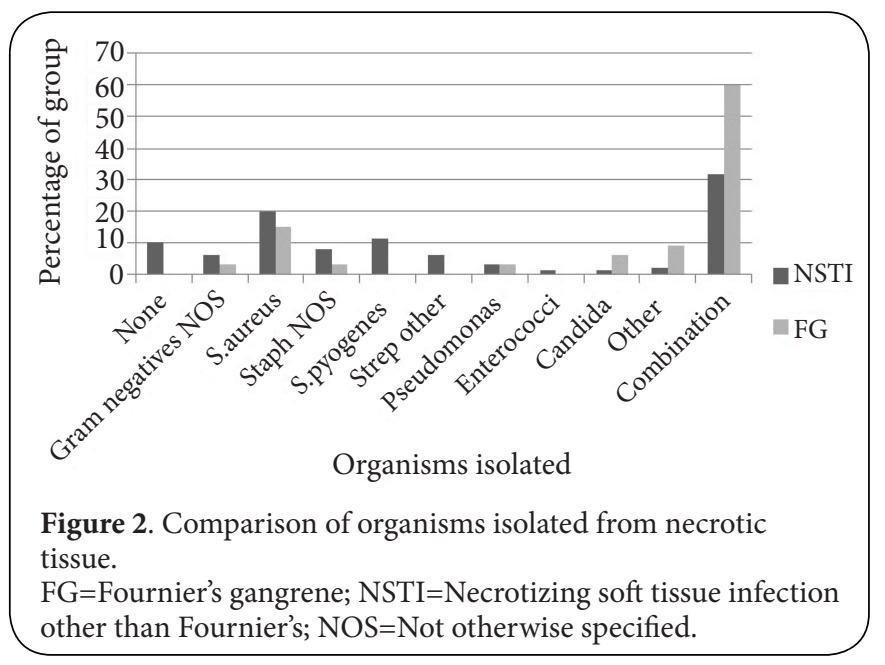

Mean time to diagnosis was 1.4 days in FG and 1.1 days in NSTI. Both groups were also taken to the operating room (OR) within a similar length of time; the FG group were brought to the OR in a mean of 1.7 days while those with NSTI group were brought in a mean of 1.5 days. There was, however, a difference found in the course of treatment following surgery. Those with FG had a mean of 4.4 operations while those with NSTI had 2.9 operations $(p=0.01)$. These operations were debridements or amputations. As data was only procured from the original admission, these likely did not include reconstructive surgeries such as skin grafts and flaps. These surgeries are usually performed during subsequent outpatient admissions, although this was not specifically noted in the data collection sheet. Patients in FG group had a mean length of stay (LOS) of 23 days while those in NSTI group had a mean LOS of 16 days $(p=0.01)$. The mortality rate was found to be higher in NSTI patients. Mortality was $21 \%$ in those with FG and $24 \%$ in NSTI patients. However, this was not found to be statistically significant $(\mathrm{p}=0.82)$ (Table 3 ).

Table 3. Comparison of clinical outcomes in Fournier's gangrene to NSTI in other locations.

\begin{tabular}{llll}
\hline & NSTI & FG & P-value \\
\hline Time to diagnosis (days) & $1.1(0-19)$ & $1.4(0-6)$ & 0.49 \\
Time to first surgery (days) & $1.5(0-38)$ & $1.7(0-6)$ & 0.45 \\
Number of surgeries & $3(0-9)$ & $4(0-28)$ & 0.01 \\
LOS (days) & $15.9(2-56)$ & $23.0(3-101)$ & 0.01 \\
Mortality & $24 \%$ & $21 \%$ & 0.82 \\
\hline
\end{tabular}

FG: Fournier's gangrene; NSTI: Necrotizing soft tissue infection other than Fournier's; LOS: Length of stay

\section{Discussion}

NSTIs comprise a broad spectrum of soft tissue infections which includes FG. NSTIs spread fast, and are life threatening infections with mortality rates reported to be between $15-25 \%$ in literature $[\mathbf{1}, \mathbf{2}, \mathbf{4}, \mathbf{7 - 1 0 , 2 0 ]}$. Although NSTIs and FG have been extensively researched [1-35], little data exists comparing FG separately from other NSTIs. Only one study compared FG to other NSTIs in terms of clinical outcomes similarly to our study [9]. It compared FG and NSTI in terms of successful treatment, survival rate, predisposing risk factors, and mortality. The study found that patients with FG do not differ much from other NSTIs and require same treatment principles of early recognition, resuscitation, debridement and broad-spectrum IV antibiotics. Similar to our study, they found that difference in mortality was not statistically significant. Unlike our study, they did not make a differentiation between the length of stay or the number of operations between FG and NSTI. In addition, their patient population consisted of only 55 patients of FG and NSTIs combined, while our study comprised a total of 133 patients.

Our study found that DM2 was more prevalent in FG compared to NSTI, which was expected and strongly supported by literature [26-28,36]. A proposed explanation for association with DM2 and NSTIs is the high levels of sugar in blood decreasing phagocytic and intracellular bactericidal activity and creation of neutrophil dysfunction thus leaving the patient immunocompromised [27].

Our data did not show a higher mortality rate in FG compared to other NSTIs as is found in literature. In fact, NSTI had a higher mortality rate than $\mathrm{FG}$ on average. However, this was not statistically significant. The overall reported mortality rate nationwide from NSTI is $15-25 \%$, which is very close to the data reported in this study literature $[1,2,4,7-10,20]$. The mortality rate at our institution was $21 \%$ in those with $F$ and $24 \%$ of NSTI patients ( $p=0.82$ ) (Table 3). FG mortality was reported to be as high as 30 to $40 \%$ in the past [37], but recent studies report mortality rates around $20-25 \%$ [38], which is similar to 
the results we obtained in our study. This is likely due to the fact that treatment with early, aggressive debridement has become a universal standard of care for FG, and as a result, morality rate has decreased over the last few decades.

A statistically significant higher rate of intravenous drug abuse (IVDA) in NSTIs was found compared to FG. The in creased incidence of NSTIs in IVDA has been a world-wide phenomenon in recent years that is supported by several retrospective studies [39-47]. Methods of injecting drugs into the subcutaneous region otherwise known as "skin-popping" may explain this phenomenon. Injection of a contaminated needle into the subcutaneous space is a perfect nidus for an NSTI [48]. In addition, there have been recent reports of increased use of Black Tar Heroin (BTH) associated with NSTIs [48-50]. BTH is a dense, gummy, coal-colored substance that is produced from opium grown in the mountainous regions of northern Mexico. Crude processing techniques lead to the production of a substance that is contaminated by bacteria. Injection into the subcutaneous region and muscle of $\mathrm{BTH}$ has resulted in the rise of NSTIs associated with BHT [48-50]. It is still unclear whether the multiple organisms arise from intrinsic contaminants of BTH, or if they are acquired from dirty injection needles and skin flora [49]. This does signify that a higher level of suspicion needs to exist in known IVDAs and skin infections.

Hemoglobin levels on admission were found to be lower in FG than in NSTI, as well. However, the difference is minimal (11.6 versus 10.5). Interestingly, decreased hemoglobin is one of the laboratory tests that is used in the Laboratory Risk Indicator for Necrotizing Fasciitis Score (LRINEC), a scoring system for NSTIs developed by Wong and associates [51]. The low serum hemoglobin levels are given a higher score to distinguish necrotizing fasciitis from other soft tissue infections. However, the LRINEC hemoglobin score has not been established to be lower in FG compared to other NSTIs. This is of interest, and may need to be further studied.

The average number of operations required was found to be about one operation higher in FG compared to other NSTIs. It is established that multiple returns to the operating room for second, third, and even fourth look is strongly encouraged as getting ahead of the infection and achieving eradication through debridement is standard of care. The median number of returns to the operating room nationwide is around four $[4,6,8]$. In our study, the average number of trips to the OR for NSTIs was 2.9 versus 4.4 for FG. This also corresponds to the finding that the average LOS was longer in FG. This could be explained by the fact that the location of FG in the perineum where skin folds and large body habitus can make it more difficult to achieve clear margins of infection. NSTI group patients had infections primarily located on extremities or torso which is easier to debride and establish negative margins. NSTI of the extremities are sometimes treated with an amputation, which removes the need for further surgical debridements, as well.
This study has several limitations beyond those inherent in a retrospective single-institution review. The reconstructive operations required and subsequent admissions after the initial hospital stay were not included in this study. In addition, different medical teams treat FG (General Surgery and Urology) while different teams treat other NSTIs (Orthopedics, General Surgery, Urology, Obstetrics and Gynecology) and as such, the treatment approach might vary from one team to another. However, most patients received treatment that is detailed in the methods sections above. In addition, by limiting to a single institution with relatively consistent practice patterns, the differences caused by variations in practice likely have limited impact on the results we obtained.

Sampling methods of cultures were not able to be confirmed for accuracy due to this being a retrospective study, however, the microbiological processing of samples at our institution has been standard since 2003. In addition, a limitation of our study is that it could have been possible that some cultures were false negatives as the initiation of antibiotics typically occurs immediately following suspicion of a clinical diagnosis of NSTI or FG at our institution. Furthermore, while it is preferred that tissue samples be obtained, due to individual physician variability in practice, some of the cultures may have been based on swabs of purulent fluid instead or in addition to the tissue sample. The number of specimens sent for culture would also have differed since we do not have a standard method of obtaining specimens. Therefore, there would have been some variability on number and type of specimens that were obtained for each patient, which could have affected the reliability of the culture results. As such, we cannot reliably state there was a difference in the proportion of polymicribal infections between the two groups. More experimental studies may need to be conducted to confirm such a finding.

It is also worth mentioning that NSTI and FG were diagnosed retrospectively through chart review, and we considered time to diagnosis as the first time that NSTI or FG was documented in the chart. Thus, it is quite possible that the diagnosis was made earlier than the actual time the physician was able to document the diagnosis in the chart. Therefore, our mean times to diagnosis are likely an overestimation for both groups. However, to the best of our knowledge, there is no reason to suspect that the delay in documenting a diagnosis would be different between FG and NSTI groups. In addition, for each individual patient, the time to diagnosis was expressed only in whole numbers, thus time was tracked on the scale of days and not hours, thus providing a wider window for a suspected diagnosis to not affect the mean time to diagnosis.

In addition, due to the retrospective nature of this study and the fact that the diagnosis of this disease process is a clinical one and likely varied from one physician to another, a validation of the assessment on how reliable diagnostic methods were between 2003 to 2012 was not able to be performed.

In our study, we included two patients who did not undergo 
a surgical intervention, as can be seen in Table 3. One of these patients died prior to any kind of surgical intervention could be performed; however, an NSTI was confirmed by culture. The other was watched in the hospital for six days and subsequently released without needing any surgical intervention. No patients had undergone a diverting colostomy.

\section{Conclusion}

In our retrospective single center review of patients with NSTI and $F G$, we found that patients with FG had a longer length of hospital stay, increased number of operations, and had lower hemoglobin levels. We found no difference in mortality rate between the two groups.

\section{Competing interests}

The authors declare that they have no competing interests.

Authors' contributions

\begin{tabular}{|l|c|c|c|}
\hline Authors' contributions & YP & RF & SD \\
\hline Research concept and design & -- & -- & $\checkmark$ \\
\hline Collection and/or assembly of data & -- & $\checkmark$ & $\checkmark$ \\
\hline Data analysis and interpretation & $\checkmark$ & $\checkmark$ & $\checkmark$ \\
\hline Writing the article & $\checkmark$ & $\checkmark$ & $\checkmark$ \\
\hline Critical revision of the article & $\checkmark$ & $\checkmark$ & $\checkmark$ \\
\hline Final approval of article & $\checkmark$ & $\checkmark$ & $\checkmark$ \\
\hline Statistical analysis & $\checkmark$ & $\checkmark$ & $\checkmark$ \\
\hline
\end{tabular}

\section{Acknowledgement}

The authors wish to acknowledge the assistance of the Texas Tech University Health Sciences Center Clinical Research Institute for assistance with study preparation and IRB approval, and Chance Witt and Brandon Levy for data collection.

\section{Publication history}

Editor: James William Gray, Birmingham Children's Hospital, UK. EIC: Ishtiaq Qadri, King Abdul Aziz University, Saudi Arabia. Received: 08-Jan-2015 Final Revised: 09-Mar-2015 Accepted: 11-Mar-2015 Published: 16-Mar-2015

\section{References}

1. Hakkarainen TW, Kopari NM, Pham TN and Evans HL. Necrotizing soft tissue infections: review and current concepts in treatment, systems of care, and outcomes. Curr Probl Surg. 2014; 51:344-62. | Article | PubMed Abstract | PubMed Full Text

2. Fabri PJ. Necrotizing soft tissue infections. J Am Coll Surg. 2014; 218:302 3. | Article | PubMed

3. Kaafarani HM and King DR. Necrotizing skin and soft tissue infections. Surg Clin North Am. 2014; 94:155-63. I Article I PubMed

4. Hussein QA and Anaya DA. Necrotizing soft tissue infections. Crit Care Clin. 2013; 29:795-806. I Article I PubMed

5. Shiroff $A M$, Herlitz $G N$ and Gracias $V H$. Necrotizing soft tissue infections. J Intensive Care Med. 2014; 29:138-44. | Article I PubMed

6. Mullangi PK and Khardori NM. Necrotizing soft-tissue infections. Med Clin North Am. 2012; 96:1193-202. | Article | PubMed

7. Jacoby I. Necrotizing soft tissue infections. Undersea Hyperb Med. 2012; 39:739-52. | PubMed

8. Howell GM and Rosengart MR. Necrotizing soft tissue infections. Surg Infect (Larchmt). 2011; 12:185-90. | Article | PubMed

9. Martinschek A, Evers B, Lampl L, Gerngross H, Schmidt R and Sparwasser
C. Prognostic aspects, survival rate, and predisposing risk factors in patients with Fournier's gangrene and necrotizing soft tissue infections: evaluation of clinical outcome of 55 patients. Urol Int. 2012; 89:173-9. | Article I PubMed

10. Elliott DC, Kufera JA and Myers RA. Necrotizing soft tissue infections. Risk factors for mortality and strategies for management. Ann Surg. 1996; 224:672-83. | Article | PubMed Abstract | PubMed Full Text

11. Sawyer RG. Treatment for Necrotizing Soft-Tissue Infections: More Skin in the Game. JAMA Surg. 2014. I Article I PubMed

12. Kobayashi L, Konstantinidis A, Shackelford S, Chan LS, Talving P, Inaba $K$ and Demetriades $D$. Necrotizing soft tissue infections: delayed surgical treatment is associated with increased number of surgical debridements and morbidity. J Trauma. 2011; 71:1400-5. | Article | PubMed

13. Mills MK, Faraklas I, Davis C, Stoddard GJ and Saffle J. Outcomes from treatment of necrotizing soft-tissue infections: results from the National Surgical Quality Improvement Program database. Am J Surg. 2010; 200:790-6. | Article | PubMed

14. Boyer A, Vargas F, Coste F, Saubusse E, Castaing Y, Gbikpi-Benissan G, Hilbert $G$ and Gruson D. Influence of surgical treatment timing on mortality from necrotizing soft tissue infections requiring intensive care management. Intensive Care Med. 2009; 35:847-53. | Article | PubMed

15. Marszal $M$ and Bielecki K. [Necrotizing dermatitis, infections of soft tissue and deep fascia: classification and treatment]. Wiad Lek. 1998; 51:64-70. | PubMed

16. Hsiao GH, Chang $\mathrm{CH}$, Hsiao CW, Fanchiang JH and Jee SH. Necrotizing soft tissue infections. Surgical or conservative treatment? Dermatol Surg. 1998; 24:243-7. | Article | PubMed

17. Freischlag JA, Ajalat $G$ and Busuttil RW. Treatment of necrotizing soft tissue infections. The need for a new approach. Am J Surg. 1985; 149:751-5. | PubMed

18. Gauzit R. [Necrotizing skin and soft tissue infections: definitions, clinical and microbiological features]. Ann Fr Anesth Reanim. 2006; 25:967-70. | Article I PubMed

19. Elliott D, Kufera JA and Myers RA. The microbiology of necrotizing soft tissue infections. Am J Surg. 2000; 179:361-6. | $\underline{\text { Article | PubMed }}$

20. Carroll PR, Cattolica EV, Turzan CW and McAninch JW. Necrotizing soft-tissue infections of the perineum and genitalia. Etiology and early reconstruction. West J Med. 1986; 144:174-8. | PubMed Abstract | PubMed Full Text

21. Sarkis P, Farran F, Khoury R, Kamel G, Nemr E, Biajini J and Merheje S. [Fournier's gangrene: a review of the recent literature]. Prog Urol. 2009; 19:75-84. | Article | PubMed

22. Riegels-Nielsen P. [Fournier's gangrene--a review]. Nord Med. 1985; 100:264-5. I PubMed

23. Dunaif CB. Fournier's Gangrene. Report of a Case and Review of the Literature. Plast Reconstr Surg. 1964; 33:84-92. I PubMed

24. Nickel JC and Morales A. Necrotizing fasciitis of the male genitalia (Fournier's gangrene). Can Med Assoc J. 1983; 129:445-8. I PubMed Abstract | PubMed Full Text

25. Mabry RM and Harwood AL. Fournier's disease: necrotizing gangrene of the male genitalia. J Emerg Med. 1983; 1:133-6. | Article | PubMed

26. Aslanidis T, Myrou A and Giannakou-Peftoulidou M. Management of a young female patient with Fournier's gangrene and Lemierre's syndrome. Pan Afr Med J. 2014; 18:275. | Article | PubMed Abstract | PubMed Full Text

27. Hasdemir AO, Buyukasik O and Col C. The clinical characteristics of female patients with Fournier's gangrene. Int Urogynecol J Pelvic Floor Dysfunct. 2009; 20:1439-43. | Article | PubMed

28. Czymek R, Frank P, Limmer S, Schmidt A, Jungbluth T, Roblick U, Burk C, Bruch HP and Kujath P. Fournier's gangrene: is the female gender a risk factor? Langenbecks Arch Surg. 2010; 395:173-80. | Article | PubMed

29. Nisbet AA and Thompson IM. Impact of diabetes mellitus on the presentation and outcomes of Fournier's gangrene. Urology. 2002; 60:775-9. | Article | PubMed 
30. Archer MI. Diabetes mellitus and Fournier's gangrene. Diabet Med. 1986; 3:268-9. | Article | PubMed

31. Dootson GM, Loot CW and Moisey CU. Fournier's gangrene and diabetes mellitus: survival following surgery. J R Soc Med. 1982; 75:916-7. | PubMed Abstract | PubMed Full Text

32. Lisovoi RV, Zvonok IS, Danilko AN and Ivonin IE. [Experience of Fournier's gangrene treatment]. Klin Khir. 2010; 104-5. | PubMed

33. Fillo J, Cervenakov I, Labas P, Mardiak J, Szoldova K, Kopecny M, Szeiff S, Mal'a $\mathrm{M}$ and Chovan $\mathrm{D}$. Fournier's gangrene: can aggressive treatment save life? Int Urol Nephrol. 2001; 33:533-6. | Article I PubMed

34. Wolach MD, MacDermott JP, Stone AR and deVere White RW. Treatment and complications of Fournier's gangrene. Br J Urol. 1989; 64:310-4. | Article | PubMed

35. Aberle B, Figdor PP and Millesi H. [Treatment of Fournier's gangrene of the scrotum]. Urologe. 1971; 10:166-8. | PubMed

36. Lamerton AJ. Fournier's gangrene: non-clostridial gas gangrene of the perineum and diabetes mellitus. J R Soc Med. 1986; 79:212-5. | PubMed Abstract | PubMed Full Text

37. Mastroeni F, Novella G, Curti P, D’Amico A, Lusardi L, Porcaro AB and Tallarigo $C$. [Fournier's gangrene: report of 2 cases and review of the literature]. Arch Ital Urol Androl. 1999; 71:31-4. I Article I PubMed

38. Ersay A, Yilmaz G, Akgun $Y$ and Celik Y. Factors affecting mortality of Fournier's gangrene: review of 70 patients. ANZ J Surg. 2007; 77:43-8. | Article I PubMed

39. Anaya DA, McMahon K, Nathens AB, Sullivan SR, Foy $H$ and Bulger E. Predictors of mortality and limb loss in necrotizing soft tissue infections. Arch Surg. 2005; 140:151-7. | Article I PubMed

40. Cainzos M and Gonzalez-Rodriguez FJ. Necrotizing soft tissue infections. Curr Opin Crit Care. 2007; 13:433-9. | Article I PubMed

41. Yaghoubian A, de Virgilio C, Dauphine C, Lewis RJ and Lin M. Use of admission serum lactate and sodium levels to predict mortality in necrotizing soft-tissue infections. Arch Surg. 2007; 142:840-6. | Article | PubMed

42. Cuschieri J. Necrotizing soft tissue infection. Surg Infect (Larchmt). 2008; 9:559-62. | Article I PubMed

43. Frazee BW, Fee C, Lynn J, Wang R, Bostrom A, Hargis C and Moore P. Community-acquired necrotizing soft tissue infections: a review of 122 cases presenting to a single emergency department over 12 years. J Emerg Med. 2008; 34:139-46. I Article I PubMed

44. Abbott IJ and Spelman D. Bacteriology and management of necrotizing soft tissue infections. J Emerg Med. 2009; 37:420-1; author reply 421-2. | Article | PubMed

45. Licursi M, Leuzzi S, Fiumara F, Soliera M, Galati M, Piazzese E, Pirrone $G$ and Angio LG. [Necrotizing soft tissue infections in intravenous drug users]. G Chir. 2009; 30:257-68. I PubMed

46. Sanchez-Porto A, Martin-Gomez M, Casanova-Roman M, Casas-Ciria J and Nacle B. Necrotizing soft-tissue infections in a general hospital. Infez Med. 2010; 18:191-2. | PubMed

47. Steensma EA, Ertl CW and Burke LH. Clostridium tertium isolated from a necrotizing soft tissue infection in a diabetic but otherwise nonimmunocompromised patient. J Am Col Certif Wound Spec. 2011; 3:42-4. | Article | PubMed Abstract | PubMed Full Text

48. Kimura AC, Higa JI, Levin RM, Simpson G, Vargas Y and Vugia DJ. Outbreak of necrotizing fasciitis due to Clostridium sordellii among black-tar heroin users. Clin Infect Dis. 2004; 38:e87-91. | Article | PubMed

49. Dunbar NM and Harruff RC. Necrotizing fasciitis: manifestations, microbiology and connection with black tar heroin. J Forensic Sci. 2007; 52:920-3. | Article | PubMed

50. Lonergan S, Rodriguez RM, Schaulis M and Navaran P. A case series of patients with black tar heroin-associated necrotizing fasciitis. J Emerg Med. 2004; 26:47-50. | Article I PubMed

51. Kulkarni M, Vijay Kumar G, Sowmya G, Madhu C and Ramya S. Necrotizing Soft-Tissue Infection: Laboratory Risk Indicator for Necrotizing Soft Tissue Infections Score. J Lab Physicians. 2014; 6:46-49. | Article | PubMed Abstract | PubMed Full Text
Citation:

Puckett Y, Fisher B and Dissanaike S. Clinical comparison of fournier's gangrene to other necrotizing soft tissue infections. Res J Infect Dis. 2015; 3:1. http://dx.doi.org/10.7243/2052-5958-3-1 